\title{
DAMPING OF SUBSYNCHRONOUS RESONANCE OSCILLATIONS USING THE VOLTAGE MAGNITUDE AND PHASE ANGLE CONTROL OF STATIC PHASE SHIFTER
}

\author{
Gaber El-Saady ${ }^{(1)}$; Ashraf M. Hemeida ${ }^{(2)}$ and M. Farouk ${ }^{(3)}$ \\ (1) Elect. Eng. Depart., Faculty of Engineering, Assiut University, Assiut, Egypt \\ (2) EE. Depart., Higher Institute of Energy., South Valley Univ., Aswan, Egypt. \\ (3) Rural Electrification Authority, Cairo, Egypt.
}

(Received July 1, 2006 Accepted September 4, 2006)

\begin{abstract}
The voltage magnitude and phase Angle control of static phase shifter (VMPA-SPS) to damp the subsynchronous resonance(SSR) oscillations is investigated. A linear mathematical model of seriescompensated transmission line power system with static phase shifter is developed.The input control signals to the simulated power system is the phase angle and voltage magnitude deviations of static phase shifter. A controllability measure based on singular value decomposition (SVD) is used to identify the effectiveness of each control input signal on the electromechanical modes. A state feedback supplementary controller based on the linear quadratic regulator principle with a full rank observer is used to modulate the voltage magnitude and phase angle deviations of SPS to stabilize the SSR modes under different operating conditions and compensation levels of the compensated transmission line. To validate the effectiveness of the proposed supplementary controller, the studied power system is subjected to different disturbances. The digital simulation results prove the powerful of the proposed static phase shifter supplementary controller in terms of the fast damping of the SSR oscillations with less overshoot/undershoot.
\end{abstract}

\section{I- INTRODUCTION}

Fixed Capacitors have long been used to increase the steady state power transfer capabilities of transmission lines. A major concern associated with fixed series capacitors is the subsynchronous resonance (SSR) phenomenon which arise as a result oh the interaction between the compensated transmission line and turbine generator shaft. This results in excessively high oscillatory torque on machine shafts causing their fatigue and damage. The first two shaft failures due to SSR occurred at the Mohave station in 1970 and 1971[1], [2] since that numerous countermeasures have been used to damp SSR such as blocking filters, excitation controllers, dynamic filters, thyristor-controlled series compensator (TCSC), static phase shifter (SPS), and many other flexible AC transmission systems (FACTS) devices[3-14]. Considerable studies have been conducted in using phase angle control of SPS(PA-SPS) to damp out SSR modes oscillations [15], [16]. While the voltage magnitude and phase angle control 
schemes of the SPS is still limited in improvement of power system dynamic performance[4,8].The present paper introduces a comprehensive assessment of the effectiveness of the VMPA-SPS to damp out the SSR oscillations. A controllability measure based on singular value decomposition (SVD) is used to identify the effectiveness of each voltage magnitude and phase angle of SPS as a control input signal on the SSR oscillations. A linear quadratic regulator LQR is used to regulate both the voltage magnitude and phase angle deviations for enhancing the stability of the system. The full order observer is designed to estimate the power system states to be used with feedback gains obtained from LQR for synthesizing the control signals.

\section{2- STUDIED POWER SYSTEM MODELING}

Figure 1 shows a single line diagram of series capacitor -compensated power system with an SPS . To design the supplementary controller for SPS for damping the SSR oscillations the mathematical model of the studied power system with SPS is developed, The following sections explain the model of power system without SPS in state space form and also the derivation of linearized model of SPS is established.

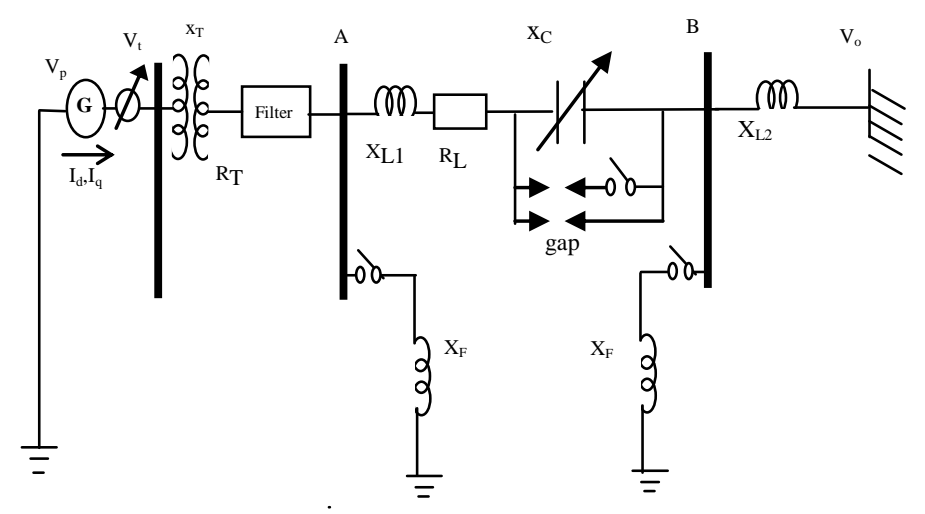

Fig. 1. IEEE first benchmark model with SPS.

\section{1- Power System Model Without SPS}

The dynamic nonlinear of IEEE first Benchmark model with series capacitor compensated transmission line as shown in Fig. $\mathbf{1}$ which combines the mass-spring system (six masses), armature and field windings, damping windings, excitation system, governor system, and the capacitor compensated transmission line is established .The nonlinear model is linearized about certain operating point. A set of 27 order linearized dynamic equations for the system without SPS is obtained and put in state space form as follows [2]:

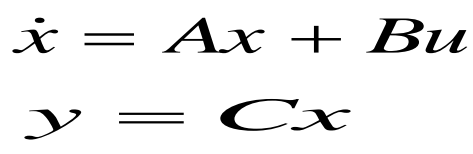

Where, $\mathrm{x}$ is the state vector and defined by: 


$$
\begin{aligned}
X= & {\left[\Delta W_{H}, \Delta \theta_{H}, \Delta W_{I}, \Delta \theta_{I}, \Delta W_{A}, \Delta \theta_{A}, \Delta W_{B},\right.} \\
& \Delta \theta_{B}, \Delta W, \Delta \theta, \Delta W_{X}, \Delta \theta_{X}, \Delta a, \Delta g, \Delta T_{H}, \Delta T_{I}, \\
& \Delta T_{A}, \Delta e_{c d}, \Delta e_{c q}, \Delta I_{d}, \Delta I_{q}, \Delta I_{f}, \Delta I_{D}, \Delta I_{Q}, \\
& \left.\Delta I_{S}, \Delta V_{R}, \Delta E_{f d}\right]^{T}
\end{aligned}
$$

While A, B, and C are constant matrix and vectors depend upon the power system parameters and operating conditions.

\section{2- Static Phase Shifter Model}

The static phase shifter SPS comprises a magnetizing transformer $T_{1}$ connected in shunt, series transformer $\mathrm{T}_{2}$ and a switching network (converters) as shown in Fig. 2. the magnitude and phase shift are obtained by extracting the line-to-ground voltage of one phase and injecting a portion of it -which is selected by the switching network- in series with another phase. Therefore the voltage magnitude and phase shift control can be obtained. To develop SPS Model the following simplified figures is considered [14].

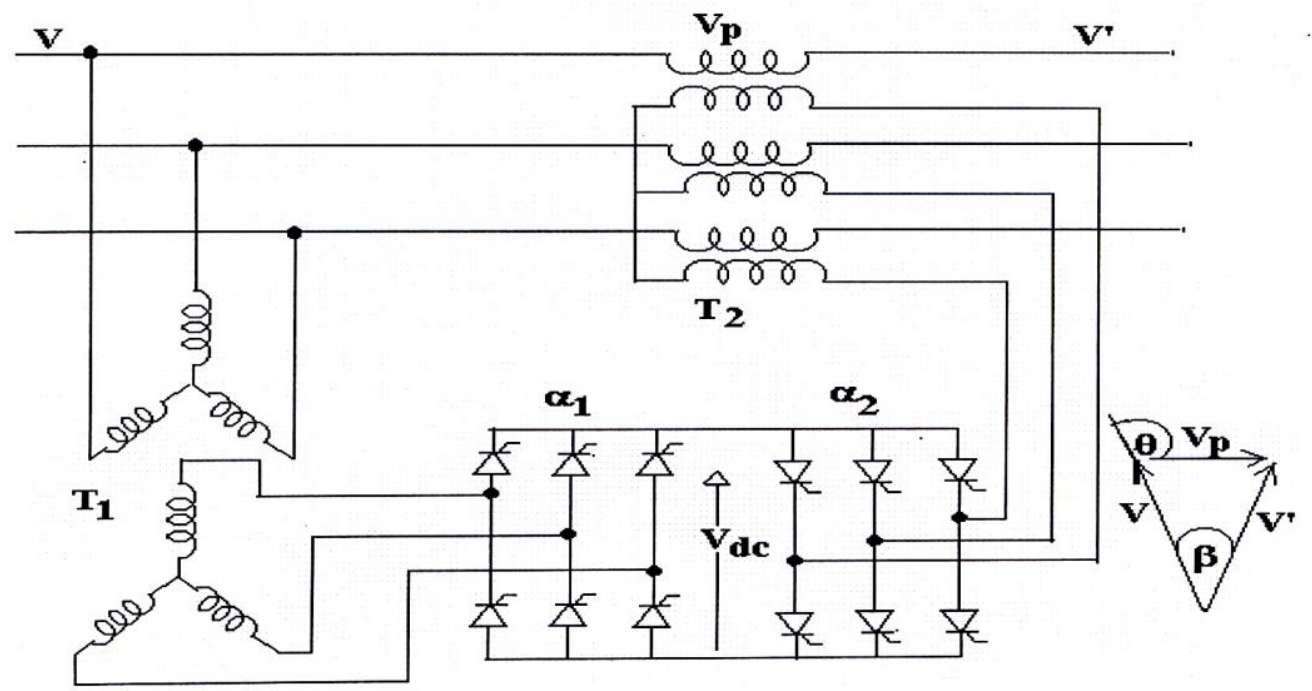

Fig. 2: A phase shifter configuration.

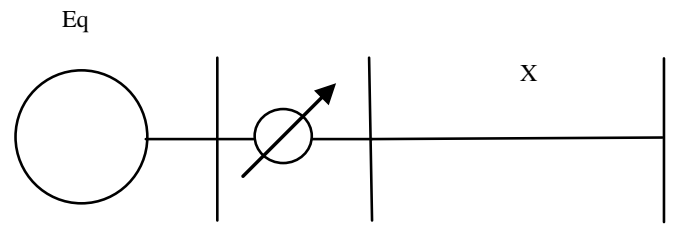

Fig. 3a: simplified system diagram. 


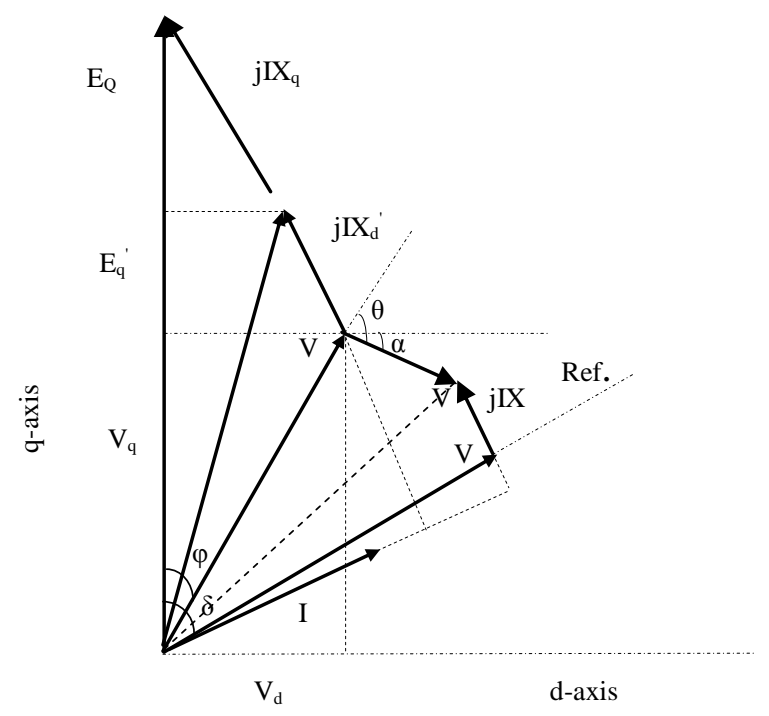

Fig 3.b: Phasor diagram of the system.

Terminal voltage in terms of direct and quadrature components is given by:

$$
V_{t}^{2}=V_{d}^{2}+V_{q}^{2}
$$

From the geometry of the phasor diagram shown in Fig. (3.b) the following equations are obtained,

$$
\begin{aligned}
& V_{d}=R I_{d}-X I_{q}+(X / \omega b) \dot{I}_{d}+e_{c d}+V_{\circ} \sin \delta-V_{p} \cos \alpha \\
& V q=X I_{d}+R I_{q}+(X / \omega b) \dot{I}_{q}+e_{c q}+V_{\circ} \cos \delta-V_{p} \sin \alpha \\
& \alpha=\theta_{p}+\phi-\frac{\pi}{2} \\
& \sin \phi=V_{d} / V_{t}
\end{aligned}
$$

The above non-linear equations are linearized and the results are:

$$
\begin{aligned}
\Delta V_{t} & =\left(V_{d \circ} / V_{t \circ}\right) \Delta V_{d}+\left(V_{q \circ} / V_{t \circ}\right) \Delta V_{q} \\
& (10) \quad V_{d}=R \Delta I_{d}-X \Delta I_{q}+(X / \omega b) \Delta \dot{I}_{d}+\Delta e_{c d}+ \\
\Delta V q & \left.=X \Delta I_{d}+R \Delta I_{q}+(X / \omega b) \Delta \dot{I}_{q}+\Delta e_{c}\right) \Delta \delta+\left(V_{P_{\circ}} \sin \alpha_{\circ}\right) \Delta \alpha-\left(\cos \alpha_{\circ}\right) \Delta V_{P} \\
& -\left(V_{\circ} \sin \delta_{\circ}\right) \Delta \delta-\left(V_{P_{\circ}} \cos \alpha_{\circ}\right) \Delta \alpha-\left(\sin \alpha_{\circ}\right) \Delta V_{P} \\
\Delta \alpha & =\Delta \theta_{p}+\Delta \phi
\end{aligned}
$$




$$
\Delta \alpha=\Delta \theta_{p}+\left(V_{t \circ} \Delta V_{d}-V_{d \circ} \Delta V_{t}\right) /\left(V_{q \circ} V_{t \circ}\right)
$$

by substituting $\Delta \alpha$ from Eq. (13)in Eqs. (10),(11) making some algebraic manipulation yields :

$$
\begin{aligned}
& \Delta V_{d}=M_{\delta} \Delta \delta+M_{\omega} \Delta \omega+M_{d} \Delta I d+M_{q}^{\Delta I} q+M_{c d} \Delta e c d \\
& +M_{c q} \Delta e_{c q}+M_{f} \Delta I_{f}+M_{D} \Delta I_{D}+M_{Q} \Delta I_{Q}+M_{s} \Delta I_{s} \\
& +M_{f d} \Delta E_{f d}+M_{\theta} \Delta \theta_{p}+M_{p} \Delta V_{p} \\
& { }_{q} V_{q}=N_{\delta} \Delta \delta+N_{\omega} \Delta \omega+N_{d} \Delta I_{d}+N_{q} \Delta I_{q}+N_{c d}{ }^{\Delta e} c d \\
& +N_{c q} \Delta e_{c q}+N_{f} \Delta I_{f}+N_{D} \Delta I_{D}+N_{Q} \Delta I_{Q}+N_{s} \Delta I_{s} \\
& +N_{f d} \Delta E_{f d}+N_{\theta} \Delta \theta_{p}+N_{p} \Delta V_{p}
\end{aligned}
$$

Where $M$ 's and $N$ 's symbols are constants.

$\Delta \mathrm{V}_{\mathrm{p}}$ is the injected voltage magnitude deviation of SPS $\Delta \theta_{\mathrm{p}}$ is the injected voltage phase shift deviation of SPS

The operation of Static Phase Shifter circuit shown in Fig. 2 can be modelled in transfer functions as shown in Fig. 4, Where K's and T's are the gain and time constant of the phase shifter circuit of $\mathrm{K}_{\mathrm{s} 1}=0.01, \mathrm{~K}_{\mathrm{s} 2}=0.1, \mathrm{~T}_{\mathrm{s} 1}=\mathrm{T}_{\mathrm{s} 2}=0.05$.

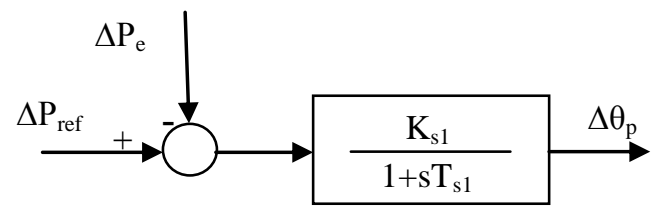

Fig. 4a: Static Phase Shifter Active Power Regulator.

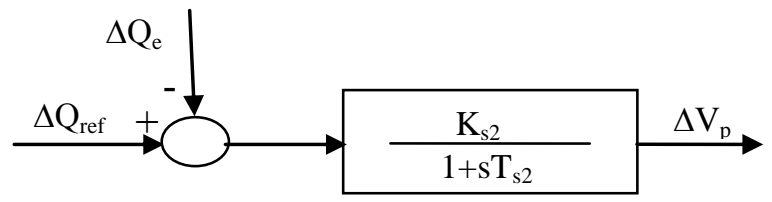

Fig. 4b: Static Phase Shifter Reactive Power Regulator.

\subsection{Studied Power System With SPS Modelling}

Substituting the linearized equations of SPS defined in eqs. $(14,15)$ in the state space equations of power system with SPS, the dynamic equations of whole system is obtained. To modulate the injected voltage magnitude and phase shift deviations of SPS, the input signals to the transfer function block diagrams of $\Delta \theta$ and $\Delta \mathrm{V}_{\mathrm{p}}$ of SPS are the differences between the reference and actual values of electrical active and reactive output powers of synchronous generator respectively as shown in Fig. 4. The electrical active and reactive output powers of the generator can be expressed by following equations : 


$$
\begin{gathered}
P_{e}=V_{d} I_{d}+V_{q} I_{q} \\
Q_{e}=V_{d} I_{q}-V_{q} I_{d}
\end{gathered}
$$

The linearized form of the above equations is given by:

$$
\begin{aligned}
& \Delta P_{e}=I_{d \circ} \Delta V_{d}+V_{d \circ} \Delta I_{d}+V_{q \circ} \Delta I_{q}+I_{q \circ} \Delta V_{q} \\
& \Delta Q_{e}=I_{q \circ} \Delta V_{d}+V_{d \circ} \Delta I_{q}-V_{q \circ} \Delta I_{d}-I_{d \circ} \Delta V_{q}
\end{aligned}
$$

Incorporating the SPS model, the State equation of the combined system will be as follows:

$$
\begin{aligned}
& x M=A M * x M+B M * U a \\
& y M=C m^{*} x M
\end{aligned}
$$

where state vector becomes

$$
\begin{aligned}
X M= & {\left[\Delta W_{H}, \Delta \theta_{H}, \Delta W_{I}, \Delta \theta_{I}, \Delta W_{A}, \Delta \theta_{A}, \Delta W_{B},\right.} \\
& \Delta \theta_{B}, \Delta W, \Delta \theta, \Delta W_{X}, \Delta \theta_{X}, \Delta a, \Delta g, \Delta T_{H}, \\
& \Delta T_{I}, \Delta T_{A}, \Delta e_{c d}, \Delta e_{c q}, \Delta I_{d}, \Delta I_{q}, \Delta I_{f}, \Delta I_{D}, \\
& \left.\Delta I_{Q}, \Delta I_{s}, \Delta V_{R}, \Delta E_{f d}, \Delta \theta_{p}, \Delta V_{p}\right]^{T}
\end{aligned}
$$

While $\mathrm{AM}$ and $\mathrm{BM}, \mathrm{CM}$ are the constant matrix and vectors of the combined system.

\section{3- PRPOSED SUPPLEMENTARY CONTROLLER DESIGN FOR SPS}

In order to damp out the SSR oscillations, the state feedback controller defined by Linear Quadratic Regulator LQR is implemented .The supplementary control signal Ua given in equation (5) is determined by $U_{a}=-K X$ Where $K$ is feedback gain vector generated from the proposed supplementary controller LQR . There are two control loops for SPS defined by $\Delta \mathrm{V}_{\mathrm{p}}$ and $\Delta \theta$ loops. To find either effective control loop of SPS where the control signal of the proposed supplementary controller is sent to it in sense that it causes more damping for SSR oscillation, the singular value decomposition SVD technique is applied. SVC is used To measure the controllability of certain mode by a given input [17]. The output of SVD technique is defined by singular value of matrix $\left[\lambda I-A: b_{i}\right]$, where $\lambda$ is the eigenvalue of $A$ matrix and $b_{i}$ is the column i of input $B$ matrix corresponding to input $i$. Minimum value of singular value indicates the capability of the $\mathrm{i}$-th input to control the mode associated with the eigenvalues $\lambda$. However, the proposed supplementary controller for SPS requires full states must be measured. Therefore an observer is designed to estimate the states of studied system.

\section{4- FULL ORDER OBSERVER DESIGN}

The state feedback supplementary controller used in this study requires all the system states must be measured. But not all the states are measurable so the observer is designed to estimate the immeasurable state variables. The full order observer to be 
described here estimates all the state variables of the system. Figure 5 shows the system-observer arrangement. From this figure the state equations of the system states $(\dot{X})$ and the estimated states $(\dot{\hat{X}})$ will be as follows :

$$
\begin{aligned}
& \dot{x}=A x-B K \hat{x} \\
& \dot{\hat{x}}=L C x+(A-B k-L C) \hat{x}
\end{aligned}
$$

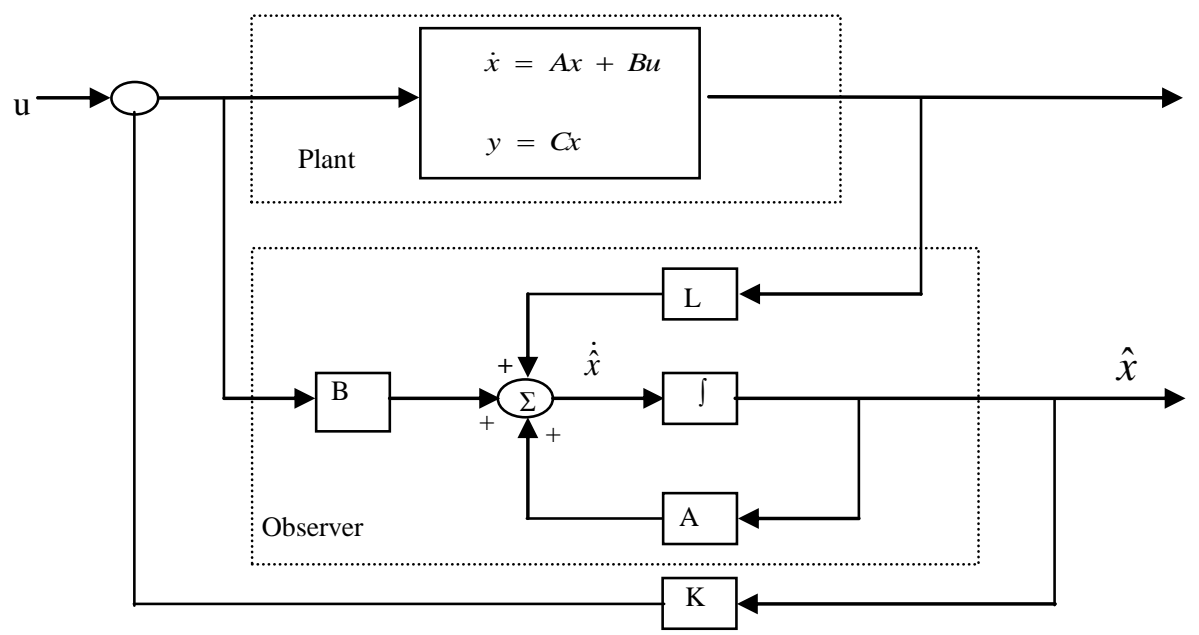

Fig. 5: Full-order observer in a state variable feedback scheme.

\section{5- DIGITAL SIMULATION RESULTS}

The data of the power system under study is found in ref[2]. Figure 6 depicts the minimum singular values with control signal sent to the $\Delta \mathrm{V}_{\mathrm{p}}$ and $\Delta \theta$ using the eigenvalues of unstable mechanical modes of SSR oscillations under different operating conditions. It is found that when the control signal is sent to both $\Delta \mathrm{V}_{\mathrm{p}}$ and $\Delta \theta$ loops simultaneously, the damping of SSR oscillations is high and quickly. Therefore the same control signal generated from the supplementary controller is added to generator active power deviation via $\Delta \theta$ loop and is added to reactive power deviation of synchronous generator through $\Delta \mathrm{V}_{\mathrm{p}}$ loop as shown in Fig. 7. To study the effectiveness of the proposed supplementary controller for SPS, the studied power system is subjected to different disturbances such as different operating conditions and series compensation levels $\left(X_{c} / X_{L}\right)$. Table 1 shows the eigenvalues of simulated power system without SPS, with SPS and without proposed supplementary controller, and the last column contains the eigenvalue of power system with SPS controlled by the proposed supplementary controller. It is noticed that the proposed supplementary controller causes all eigenvalues of the simulated power system to be stable. The dynamic equations of combined system under study is solved using Fourth order Ruge Kutta modified by Gill in MATALB Software package programs. The power system responses when the system is disturbed by applying the mechanical input signal $\Delta \mathrm{T}_{\mathrm{m}}$ of value 0.02 per unit are depicted in Figs. 8-1 : 8-8. 


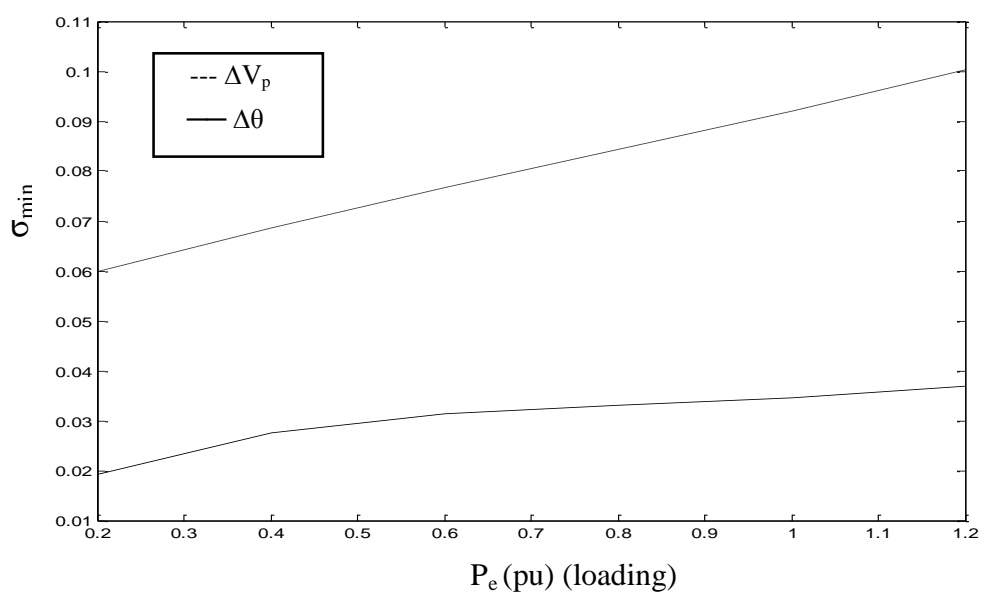

Fig. 6: Minimum singular value decomposition SVD.

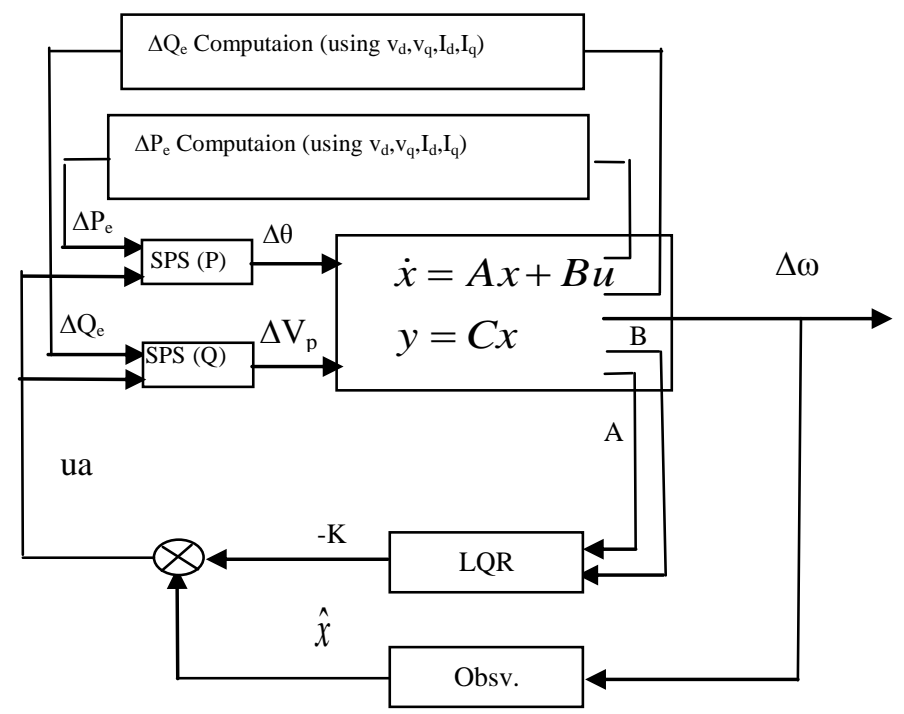

Fig. 7: Studied power system with proposed controller in block diagram.

Table 1: Studied System eigenvalues (rad/sec).

\begin{tabular}{|c|c|c|c|c|}
\hline \multicolumn{2}{|c|}{} & $\begin{array}{c}\text { Without } \\
\text { VMPA-SPS }\end{array}$ & $\begin{array}{c}\text { With VMPA-SPS but } \\
\text { without controller }\end{array}$ & $\begin{array}{c}\text { With VMPA-SPS } \\
\text { and controller }\end{array}$ \\
\hline \multirow{4}{*}{$\begin{array}{c}\text { mechanical } \\
\text { modes }\end{array}$} & $(5) \lambda_{\mathrm{HP}}$ & $-0.18 \pm \mathrm{j} 298.18$ & $-0.18 \pm \mathrm{j} 298.18$ & $-0.18 \pm \mathrm{j} 298.18$ \\
\cline { 2 - 5 } & $(4) \lambda_{\mathrm{IP}}$ & $0.17 \pm \mathrm{j} 202.63$ & $0.02 \pm \mathrm{j} 202.56$ & $-8.78 \pm \mathrm{j} 205.63$ \\
\cline { 2 - 5 } & $(3) \lambda_{\mathrm{LPA}}$ & $1.15 \pm \mathrm{j} 161.48$ & $1.64 \pm \mathrm{j} 160.82$ & $-11.43 \pm \mathrm{j} 164.56$ \\
\cline { 2 - 5 } & $(2) \lambda_{\mathrm{EXC}}$ & $-0.68 \pm \mathrm{j} 127.11$ & $-0.64 \pm \mathrm{j} 127.11$ & $-1.21 \pm \mathrm{j} 125.2$ \\
\cline { 2 - 5 } & $(1) \lambda_{\mathrm{LPB}}$ & $-0.35 \pm \mathrm{j} 99.68$ & $-0.10 \pm \mathrm{j} 99.72$ & $-19.14 \pm \mathrm{j} 93.02$ \\
\cline { 2 - 5 } & $(0) \lambda_{\mathrm{GEN}}$ & $-0.44 \pm \mathrm{j} 10.7$ & $-0 . .35 \pm \mathrm{j} 10.45$ & $-19.56 \pm \mathrm{j} 16.78$ \\
\hline
\end{tabular}




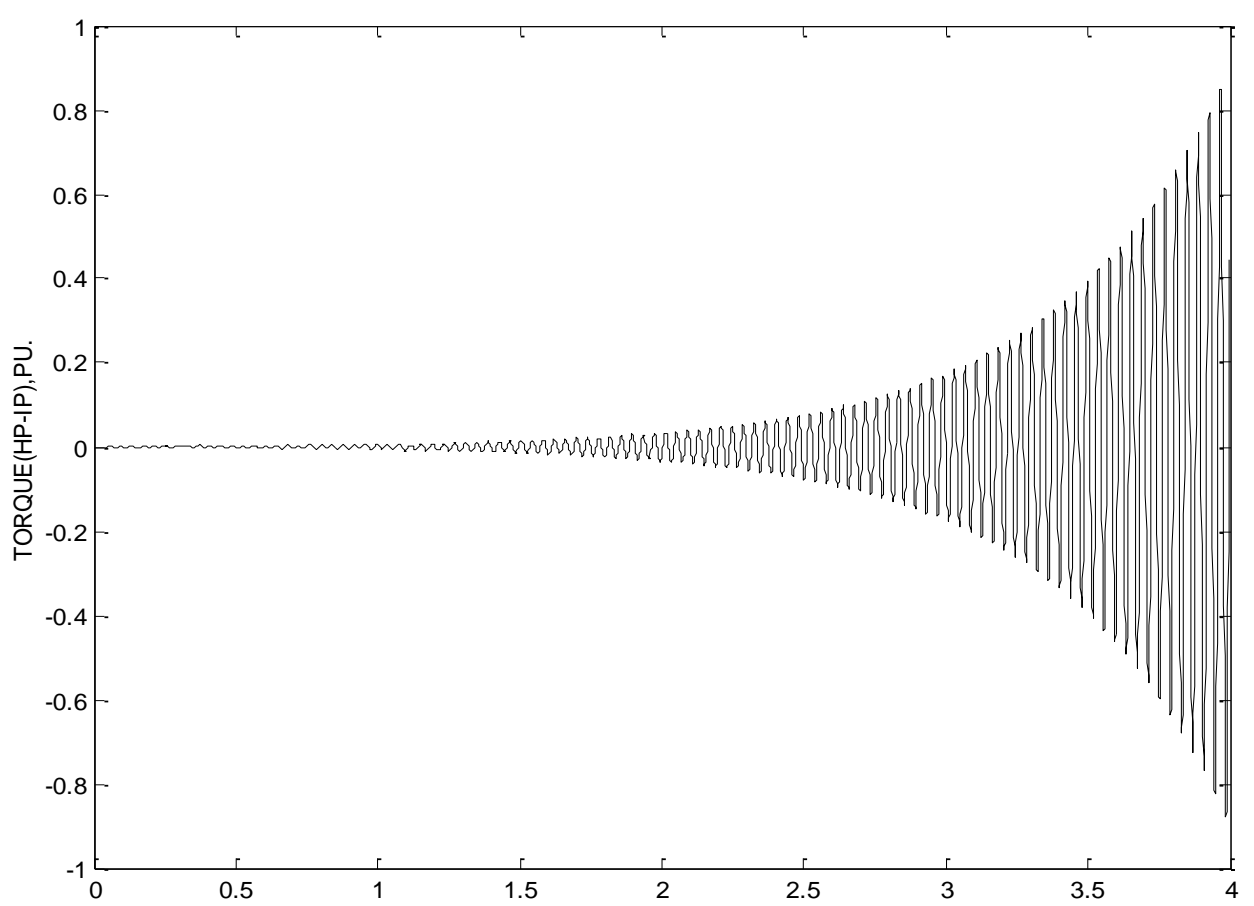

Fig. 8-1: Dynamic response of the studied system with VMPA-SRS without controller.

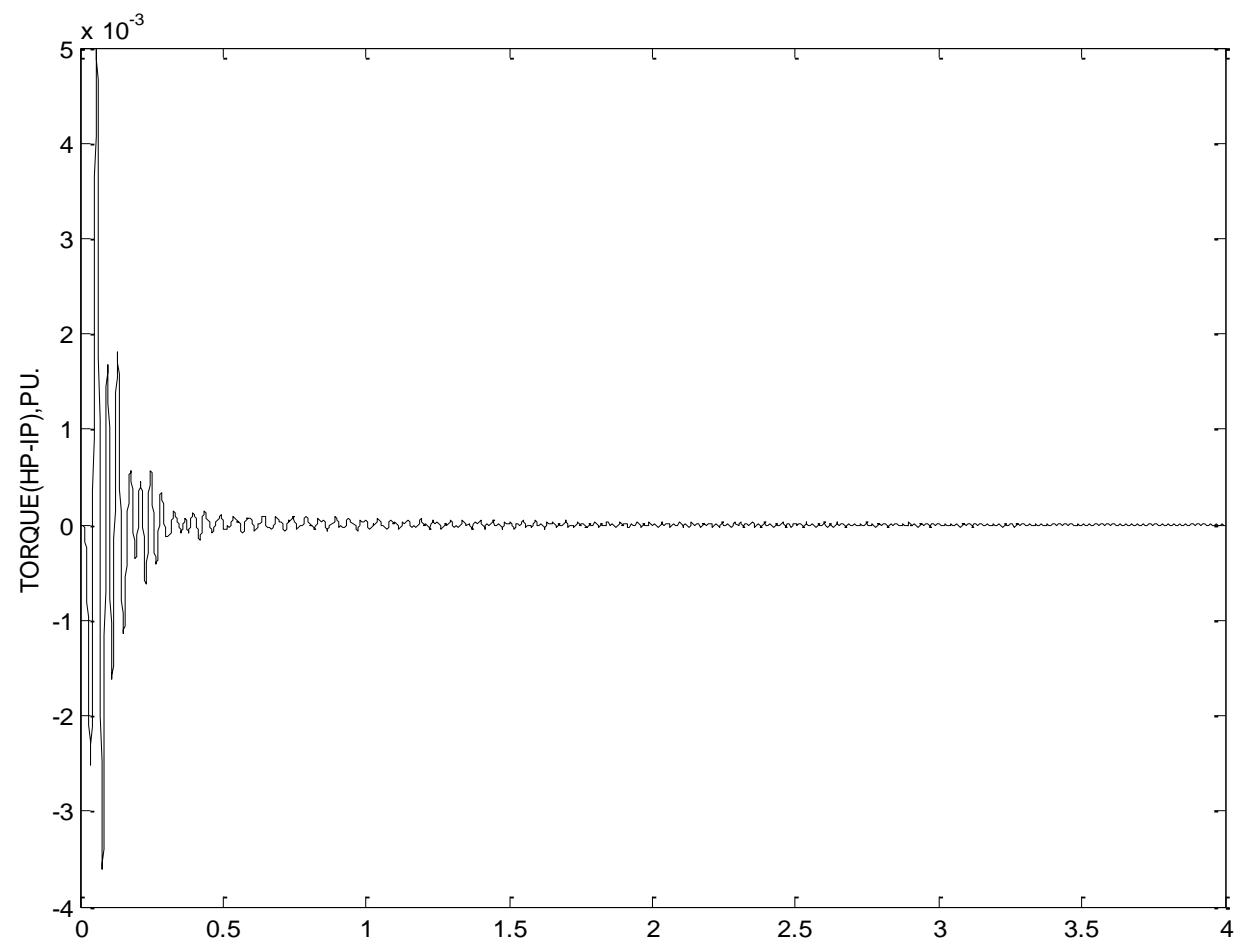


Fig. 8-2: Dynamic response of the studied system with VMPA-SRS with controller.

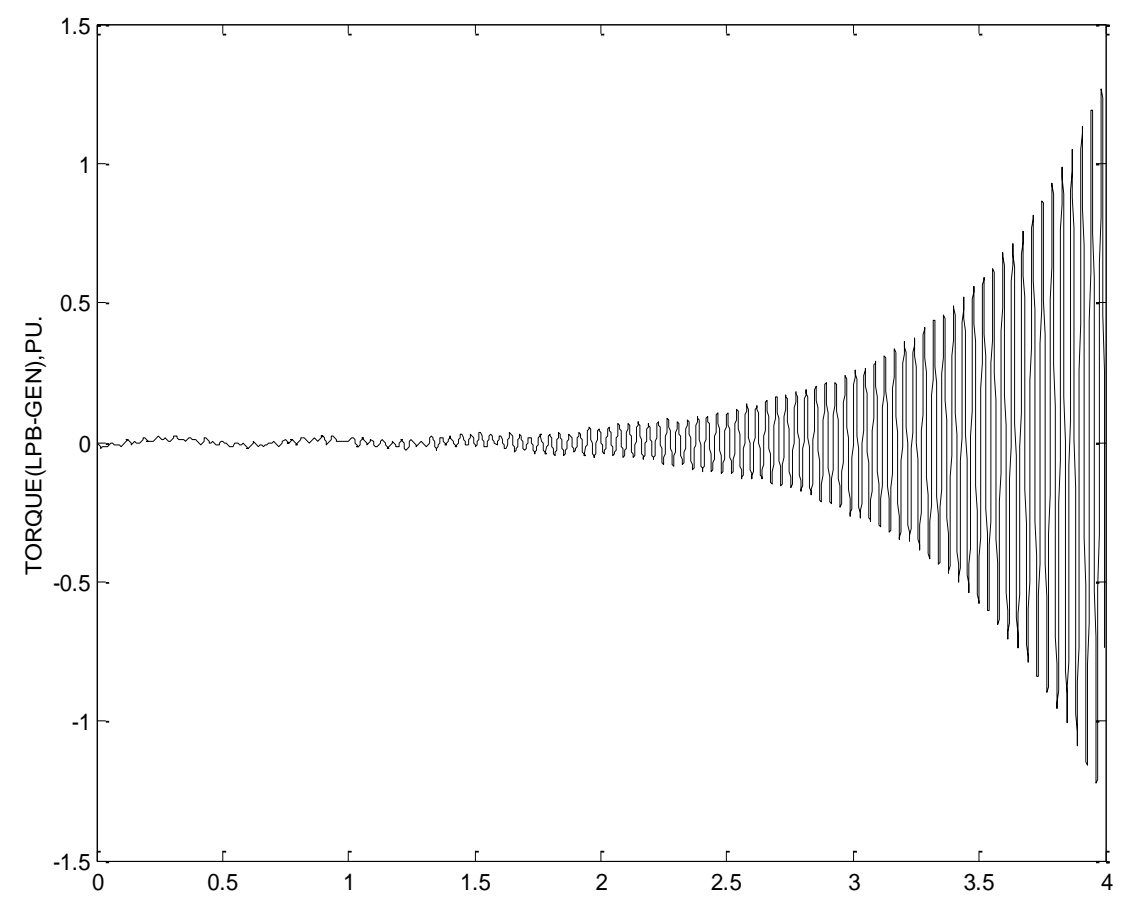

Fig. 8-3: Dynamic response of the studied system with VMPA-SRS without controller. 


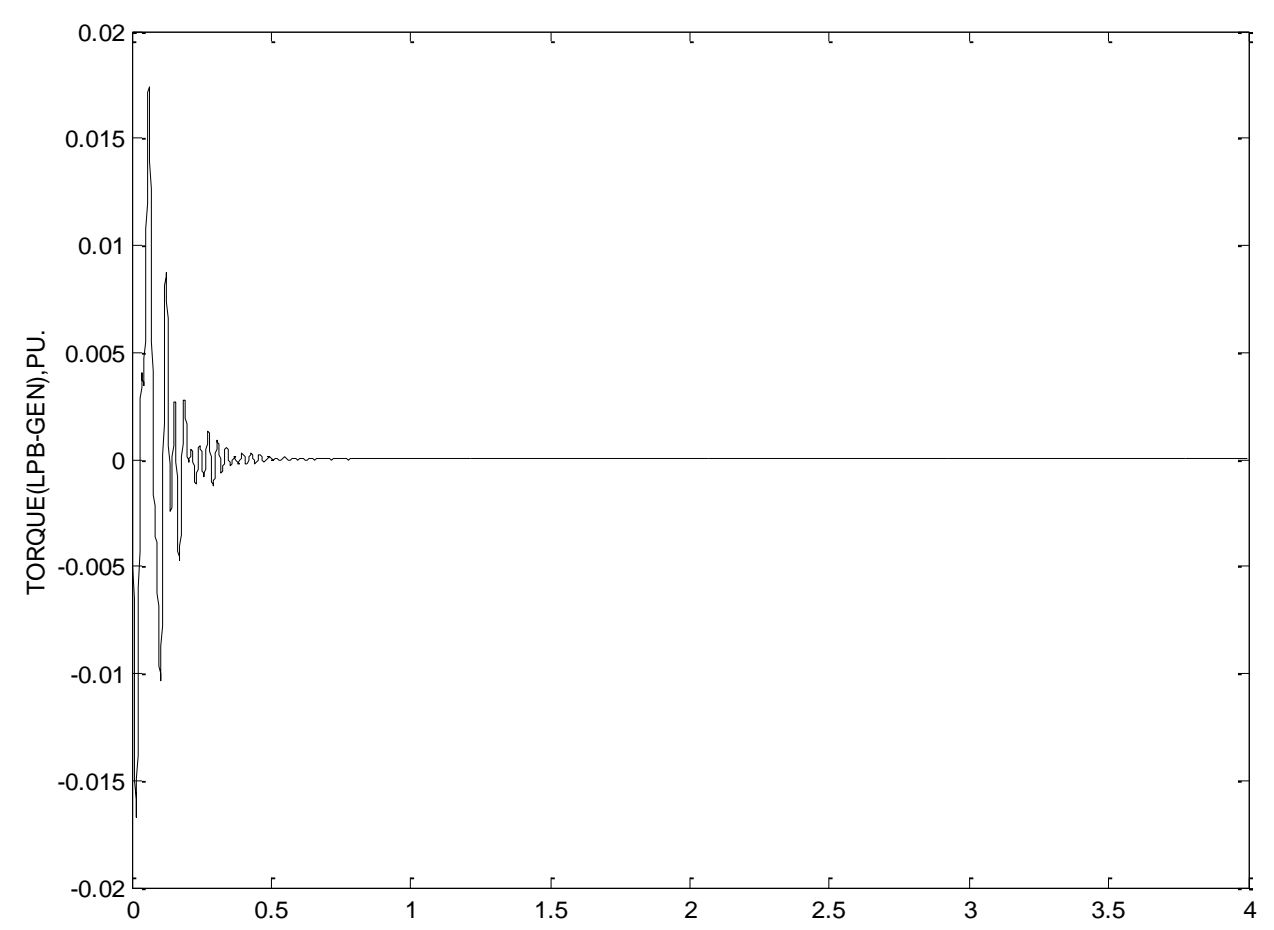

Fig. 8-4: Dynamic response of the studied system with VMPA-SRS with controller.

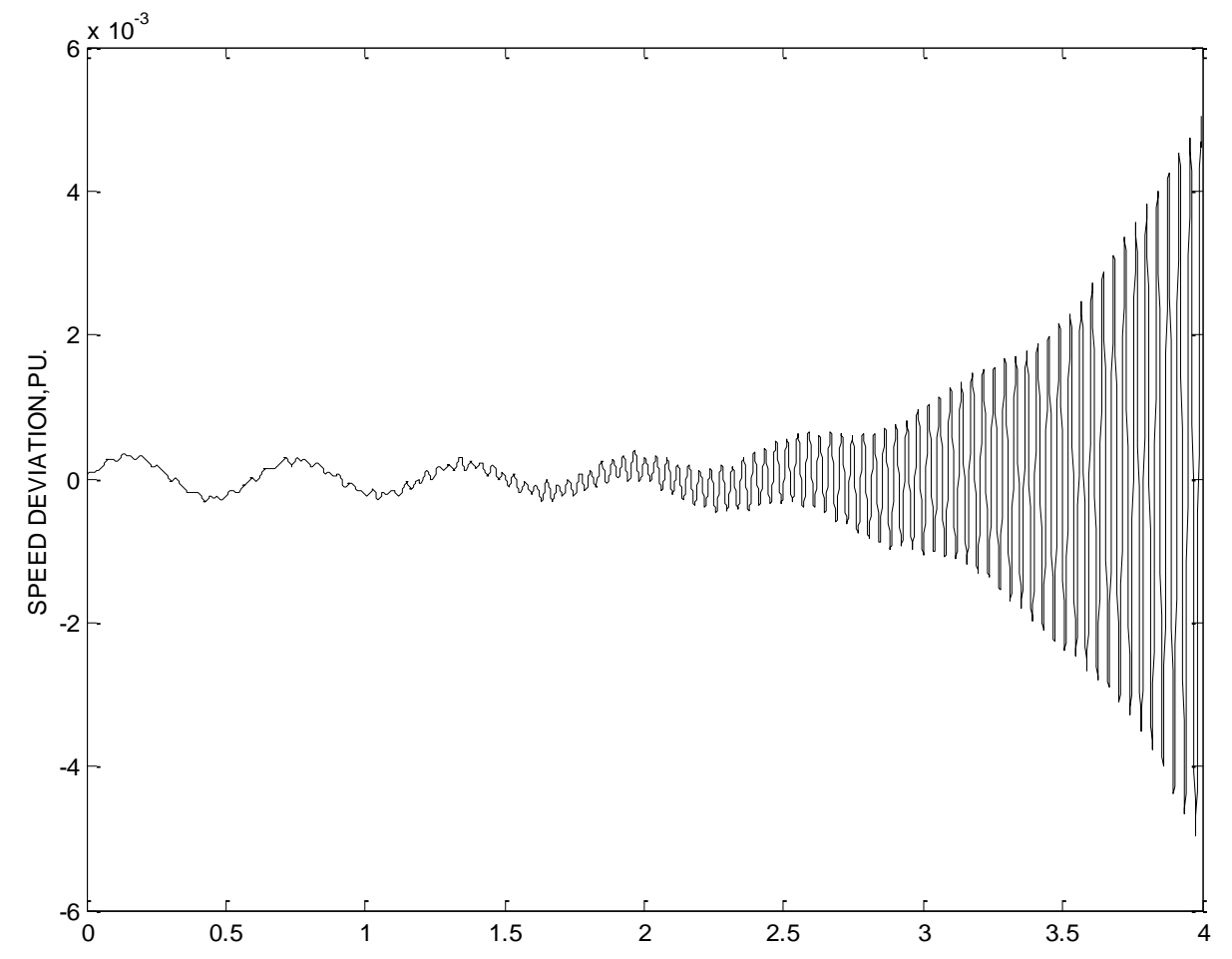


Fig. 8-5: Dynamic response of the studied system with VMPA-SRS without controller.

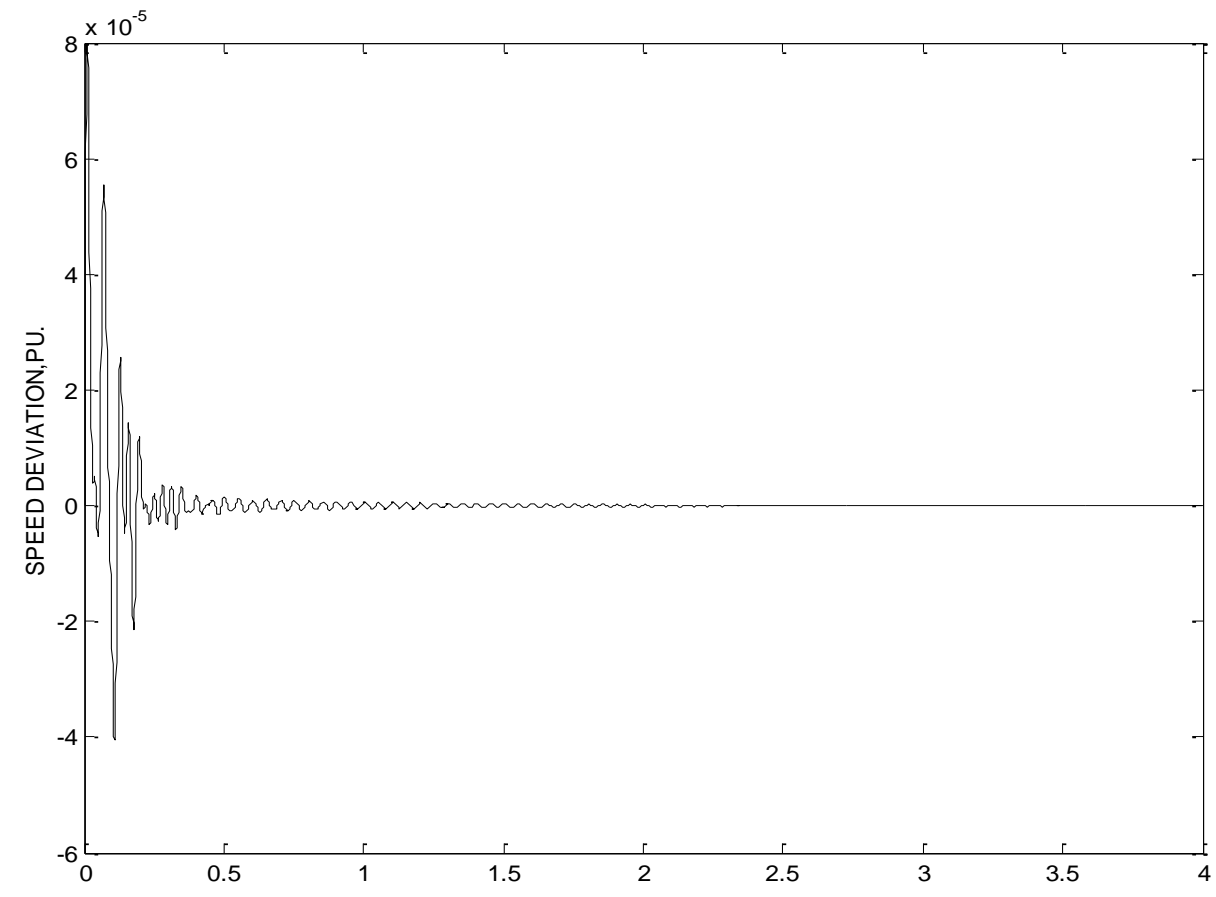

Fig. 8-6: Dynamic response of the studied system with VMPA-SRS with controller.

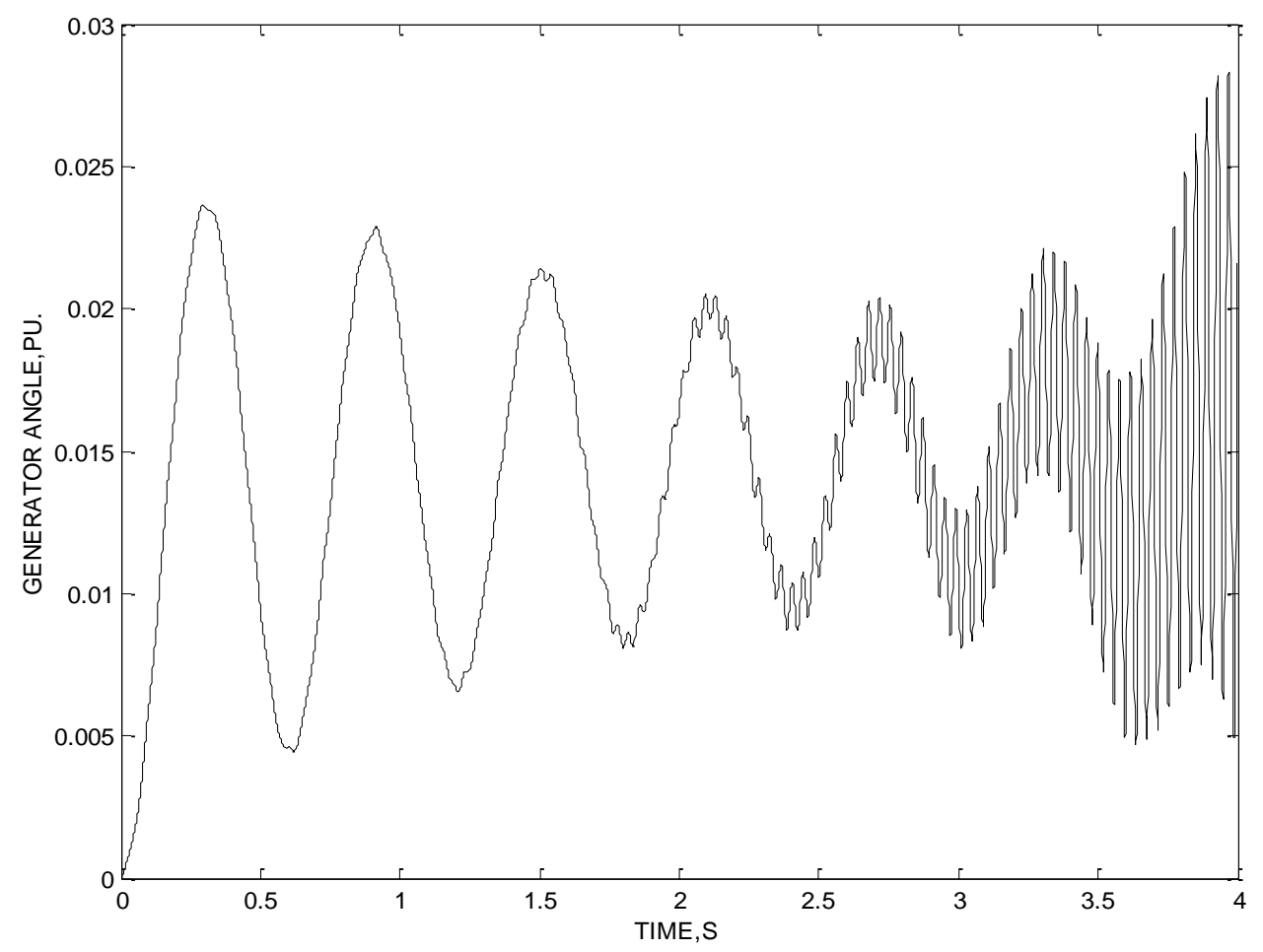


Fig. 8-7: Dynamic response of the studied system with VMPA-SRS without controller.

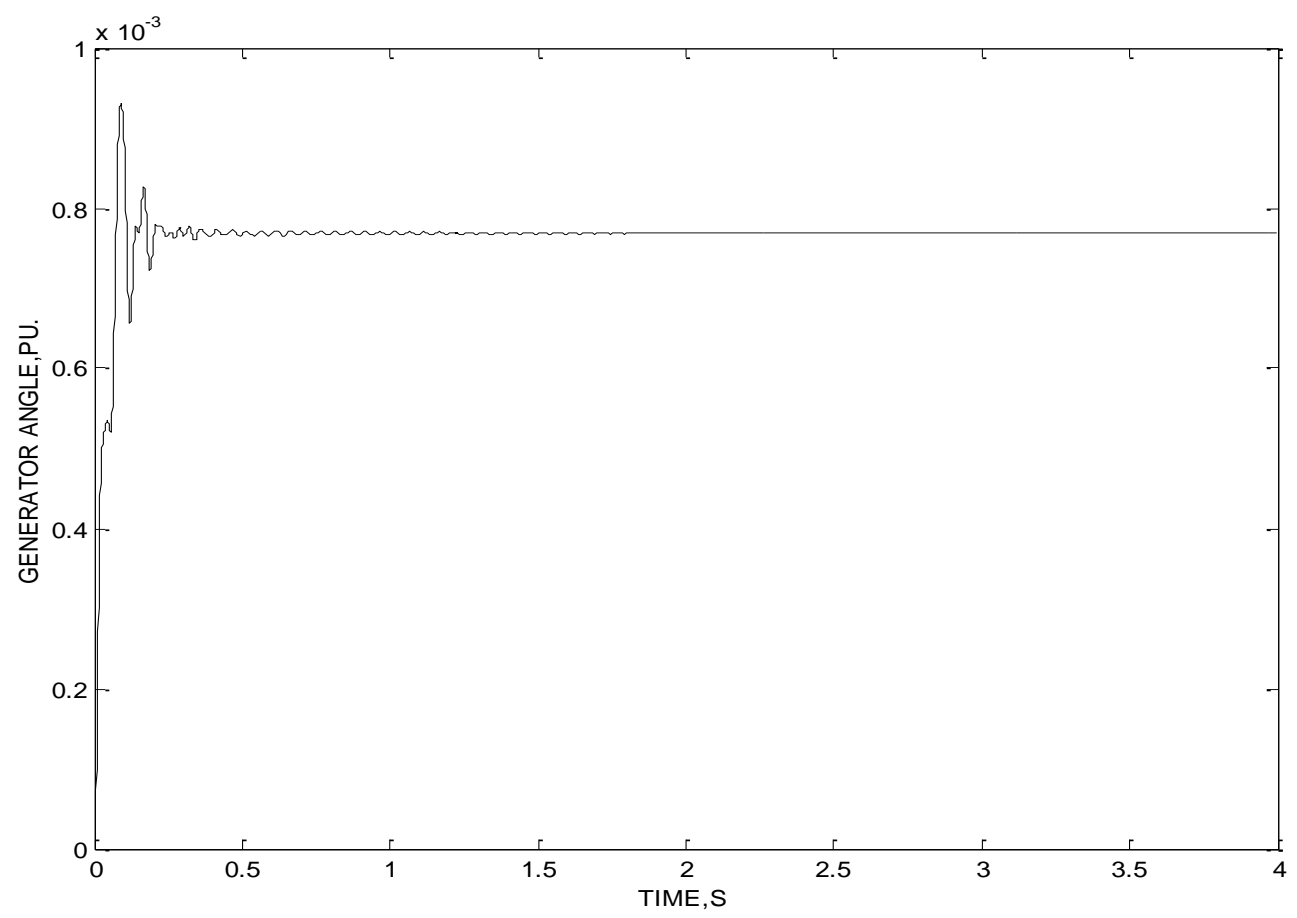

Fig. 8-8: Dynamic response of the studied system with VMPA-SRS with controller.

\section{6- CONCLUSIONS}

The present paper introduces an application of static phase shifter for damping SSR oscillations. Both the voltage magnitude and phase angle of static phase shifter are controlled simultaneously. A singular value decomposition approach is utilized to measure the capability of the certain input to control the mode associated with the selected eigenvalues. It is found that if the same control signal is sent to modulate both the voltage magnitude and the phase angle of phase shifter, the SSR Oscillations damping is quickly. A supplementary controller is designed to add a control signal to voltage magnitude and phase angle control loops. The proposed controller is installed based on linear quadratic regulator control approach. Moreover, An observer of full order is designed to estimate the power system states which are used to synthesize the control signal. Further, the power system responses after applying mechanical torque disturbance are obtained. The digital simulation results proves the effectiveness and powerful of the voltage magnitude and phase angle control of static phase shifter based on the proposed supplementary controller in terms of fast damping of SSR oscillation with less overshoot/undershoot.

\section{7- REFERENCES}

[1] R.G.Farmer,AQ.L.Schwalb,and E.katz," Navagio project report on subsynchronous resonance analysis and solution" IEEE Trans. Vol.PAS-96, pp. 1226-1232, 1977.

[2] Y.N.Yu,'Electric power system dynamic" (Academic Press,New York, 1983). 
[3] A.Ben abdennour, R.M.Hammouda, and A.A.Al-Ohaly, "Countermeasures for Self-excited torsional oscillations using reduced order robust control approach,'IEEE Tran. On Power Systems,Vol. 15, No.2, pp.779-784,May 2000.

[4] Y.Y.Hau,and L.H.Jeng," Damping of subsynchronous oscillations using adaptive controllers tuned by artificial neural networks" IEE Proceedings-C Vol. 142, No.4, pp. 415-420, July 1995.

[5] S.V.J.Kumar, A.Ghosh, and Sachchidanand," Damping of subsynchronous resonance oscillations with TCSC and PSS and their control interaction," International Journal of Electric Power Systems Research,Vol.54,pp.29-36,2000.

[6] K. Xing, and G.I. Kusic," Damping subsynchronous resonance by phase shifter", IEEE Trans. On Energy Conversion, Vol. 4, No.3, pp.344-350, Sep. 1989.

[7] Y.Y. Hsu, and C.J. Wiu , " Design of PID static VAR controller for the damping of subsynchronous oscillations ", IEEE Trans. on Energy Conversion, Vol. 3, No. 2, pp. 210-216, June 1988.

[8] Y.Y. Hsu, and L. Wang, " Modal control of an HVDC system for the damping of subsynchronous oscillations, " IEE Proc. Vol.136, Pt.C. No. 2, pp.7886, 1989.

[9] S.K. Gupta, A.K. Gupta, and N. Kumar, " Damping subsynchronous resonance in power systems," IEE Proc. Gener. Transm. Distrib. Vol. 149, No.6, pp.679688,Nov.2002.

[10] A.Tabesh,and R.Iravani,"Frequency-response analysis of torsional dynamics," IEEE Trans. on Power Systems, Vol. 19, No. 3, pp.1430-1437, Aug.2004.

[11] S.Lee, and C.C.Liu, "Damping torsional oscillations using a SIMO static VAR controller," IEE Proceedings-C, Vol. 140, No. 6, pp. 462-468, Nov. 1993.

[12] S. Lee and J. Wu," Application of superconducting magnetic energy storage unit on damping of turbogenerator subsynchronous oscillation”, IEE Proceedings-C, Vol. 138, No. 5, pp. 419-426, Sep.1991.

[13] C.J.Wu, and Y.S.Lee,"Application of simultaneous active and reactive power modulation of superconducting magnetic energy storage unit to damp turbinegenerator subsynchronous oscillations" IEEE Trans. On Energy Conversion, Vol. 8, No.1 ,pp.63-70, March, 1993.

[14] L. Wang, S.M. Lee, and C.L. Huang, "Damping subsynchronous resonance using superconducting magnetic energy storage unit," IEEE Trans. on Energy Conversion, Vol. 9, No. 4, pp. 770-777, Dec. 1994.

[15] Y.L. Kang, G.B. Shrestha, and T.T. Lie, " Improvement of power system dynamic performance with the magnitude and phase angle control of static phase shifter" International Journal of Electric Power System Research, Vol. 55, pp. 121-128, 2000.

[16] M. A. Abido, and Y.L. Abdel-Magid, " A tabu search based approach to power system stability enhancement via excitation and static phase shifter control," International Journal of Electric Power Systems Research, Vol. 52, pp.133-143, 1999.

[17] A.M.A. Hamdan, "An investigation of the significance of singular value decomposition in power system dynamics" International Journal of Elect. Power and Energy Systems, Vol. 21, pp. 417-424, 1999. 


\section{إخماد الاهتزازات الرنينية تحت التزامنية باستخدام عنصر إزاحة الطور}

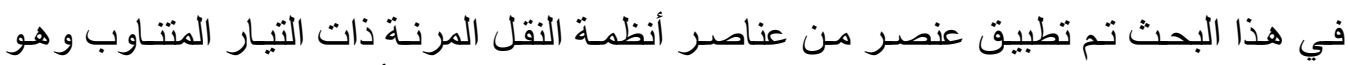

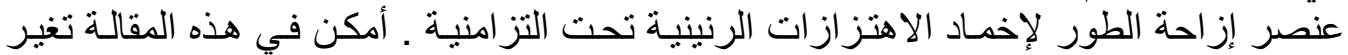
تزامني لمقدار و زاوية الجهد الذي يحدثه عنصر الإزاحة المقترح وذلك لتعديل جهد خط النه النقل

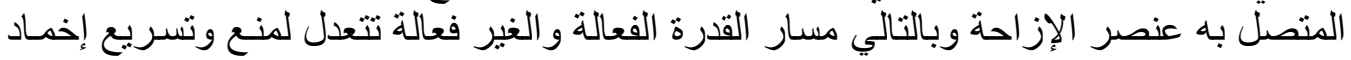

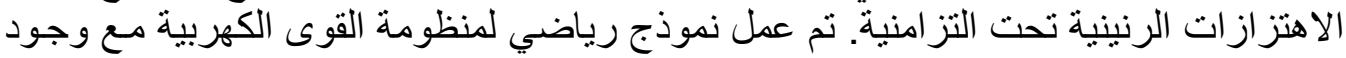

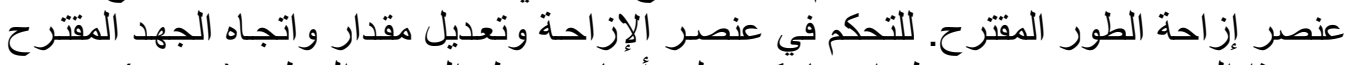

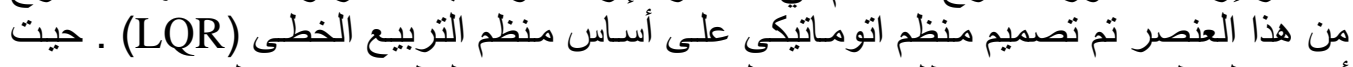

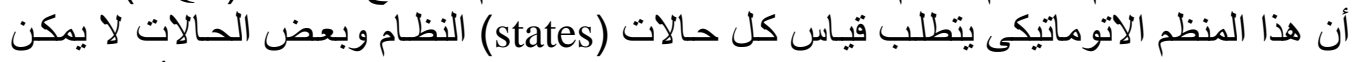

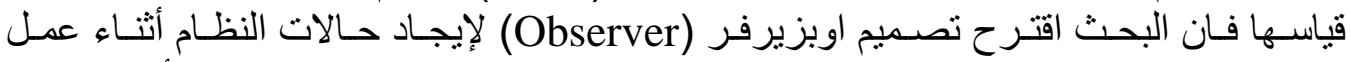

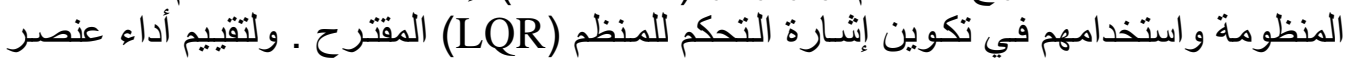

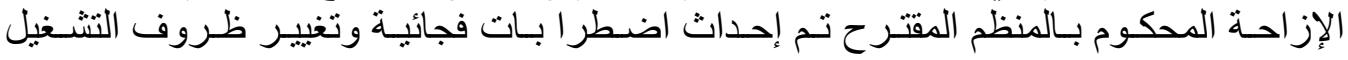

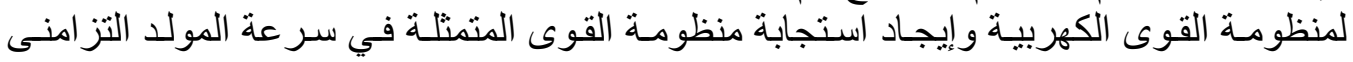

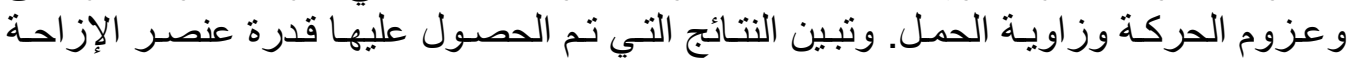

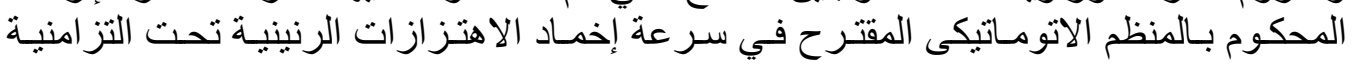
والحفاظ على استقرار منظومة القوى الكهرئية 